\title{
One-dimensional finite element limit analysis for hydraulic pile extraction $^{\star, \star \star}$
}

\author{
William J.A.P Beuckelaers ${ }^{\mathrm{a}}$, Kristine Vandenboer $^{\mathrm{a}}$, Jonas Verbraecken ${ }^{\mathrm{b}}$, Stijn François $^{\mathrm{b}}$ \\ ${ }^{a}$ Jan De Nul Group, Tragel 60, 9308 Hofstade-Aalst, Belgium \\ ${ }^{b}$ Department of Civil Engineering, KU Leuven, Leuven, Belgium
}

\begin{abstract}
This paper presents a numerical method to efficiently calculate the required overpressure for hydraulic pile extraction. The method uses a one-dimensional (1D) model involving two steps: (1) the steady state hydraulic pressure distribution is calculated for a unit pressure using a finite element model and (2) the required overpressure is calculated using finite element limit analysis. This combined model leads to an efficient calculation tool for estimating the required hydraulic overpressure to extract the pile. The model can also capture other failure mechanisms, such as failure of the pile plug, and the 1D approach allows for alternative soil resistance formulations to be incorporated easily. This allows the method to be used for preliminary analysis as well as detailed extraction assessments for an entire wind farm site. The proposed method is applied to study a pile in sand, clay and layered soil profiles. The analyses in sand show a significant increase in the plug shaft resistance due to the hydraulic gradient, resulting in a super-linear increase of break-out pressure with embedment depth. In clay soils, the break-out pressure increases linearly, but plug failure may occur at large embedment depths. Furthermore, soil layering can have a significant effect on the break-out pressure.
\end{abstract}

Keywords: Hydraulic pile extraction, One-dimensional limit analysis, Limit states.

\section{Introduction}

Offshore wind turbines are typically commissioned for a life-span of 20 to 25 years. After this period, the turbines and supporting structures are decommissioned. Offshore foundation piles are traditionally cut at several meters below the seabed, leaving the remaining steel in the ground. Alternatively, full pile extraction reduces environmental impact, allows for the re-use and recycling of steel, and avoids leaving

\footnotetext{
${ }^{\star}$ Postprint version.

${ }^{\star \star}$ Published version: W.J.A.P Beuckelaers, K. Vandenboer, J. Verbraecken, and S. François. One-dimensional finite element limit analysis for hydraulic pile extraction. Computers and Geotechnics, 133:104042, 2021.

DOI: https://doi.org/10.1016/j.compgeo.2021.104042

Email address: william.beuckelaers@jandenul.com (William J.A.P Beuckelaers)
} 
underground debris that may interfere with future site use. Methods for full pile removal include vibratory pile extraction, hydraulic pressure extraction, and soil loosening by jetting. Due to the specific soil conditions and pile geometry, one method may be preferred over others and the different methods therefore need to be assessed both technically and commercially for the site. Hydraulic pressure extraction is commonly used to remove suction caisson foundations. These foundations have been designed to accommodate pumping equipment during installation, which can then be reversed for extraction. The generally low length to diameter $(\mathrm{L} / \mathrm{D})$ ratio also limits the required pressure to extract this foundation type. Zhang et al. [1] present details of hydraulic extractions for two jackets with suction buckets in organic silt, silty clay and clay soils. Lorenti et al. [2] have performed on-shore extraction tests in a layered clay over sand profile. Regarding hydraulic pressure extraction in sandy soil conditions, Lehane et al. [3] presents one of the only studies, describing centrifuge hydraulic extraction tests in sand. All of these tests are performed on caisson foundations with a relatively small length to diameter ratio. Monopiles, which are the most common foundation type for offshore wind turbines, typically have larger L/D ratios. This raises the question whether hydraulic pressure extraction is feasible for the case of monopiles. In a recent research project, Balder et al. [4] have performed scaled hydraulic monopile extraction tests at a scale 1:30 to 1:20 in sand, clay and layered soil conditions. However, only limited results are currently publicly available. The normalised results that are published show a super-linear decrease in required hydraulic pressure as a pile is extracted in sand. The data also indicates a correlation between the required installation energy and the break-out extraction pressure. Partial excavation of the soil plug resulted in a significant decrease in the break-out pressure and when a bentonite layer was added on top of the plug, the break-out pressure increased.

This paper describes a one-dimensional (1D) finite element limit analysis (FELA) model to estimate the break-out pressure for hydraulic extraction. The model can also capture other failure mechanisms which may prevent the extraction. One of the advantages of using a 1D model is that existing axial pile capacity design methods can be incorporated. The American Petroleum Institute (API) methodology [5] is followed here although other methods such as the Imperial College Pile (ICP) [6] and the University of Western Australia (UWA) [7] methods could also be incorporated. The governing equations for the 1D model are based on an approximation of the stress distribution and failure mechanisms inside and outside of the pile. To capture the stress distribution in more detail, a 2D axisymmetric or 3D discretisation could be employed. When performing $2 \mathrm{D}$ or 3D FELA, one has to consider that associated flow rule may distort the results in frictional soils. Alternatively, when 2D or 3D finite element analysis is used, the break out pressure may be less clearly defined. 2D and 3D approaches are also harder to align with commonly used axial pile capacity methods in offshore practice.

The paper is outlined as follows: first the numerical model is described, covering the governing equations and the numerical implementation. The model is then applied to four reference soil profiles: sand, clay, sand over clay and clay over sand. These simulations illustrate the effect of different soil conditions on 
the break-out pressure, the failure mechanisms and the stress distributions in the pile-soil system. Finally, sensitivity studies are performed on the numerical accuracy with level of discretisation and on the effect that the embedded pile length has on the extraction pressure.

\section{Numerical model}

The 1D model is illustrated in Figure 1. The model consists of the internal soil plug, pile and external soil elements. An overpressure $p$ is applied inside the pile, resulting in an upwards force on the pile. The overpressure induces a hydraulic gradient inside the pile, increasing the vertical effective stresses in the soil plug. For the soil outside of the pile, this paper assumes initial vertical effective stress conditions. Interface elements are used to capture the shaft friction $\tau$ on the internal and external interfaces of the pile. Since only one dimension is used, all stresses $\sigma$ in the model refer to vertical compressive stresses and therefore, a subscript $\mathrm{v}$ is omitted for brevity. The (vertical) equilibrium equation for the internal plug reads as:

$$
\frac{\partial \sigma_{\mathrm{i}}^{\prime}}{\partial z}+\frac{\partial p_{\mathrm{i}}}{\partial z}+\frac{P_{\mathrm{i}}}{A_{\mathrm{i}}} \tau_{\mathrm{i}}=\gamma_{\mathrm{s}}^{\prime}
$$

and for the pile as:

$$
\frac{\partial \sigma_{\mathrm{p}}^{\prime}}{\partial z}-\frac{P_{\mathrm{i}} \tau_{\mathrm{i}}+P_{\mathrm{o}} \tau_{\mathrm{o}}}{A_{\mathrm{p}}}=\gamma_{\mathrm{p}}^{\prime}
$$

where subscripts o, p and i refer to outside (external soil), pile and inside (soil plug) respectively, a prime indicates the effective stress, $\gamma$ is the unit weight (where the subscript $\mathrm{s}$ refers to soil), $P_{\mathrm{i}}$ and $P_{\mathrm{o}}$ are the inner and outer pile perimeter and $A_{\mathrm{p}}$ and $A_{\mathrm{i}}$ are the cross section areas of the the pile wall and the internal plug.

The break-out pressure for pile extraction is calculated using a lower bound finite element limit analysis approach where the overpressure is found as the maximum pressure for which a static equilibrium can be found $[8,9,10]$. This is written as an optimization problem with the objective function and equality constraints arising from equilibrium, discontinuity and boundary conditions, complemented with yield inequalities:

Maximise

$$
p \quad \text { break-out pressure }
$$

Subject to:

$$
\begin{aligned}
& \mathbf{A}_{11} \boldsymbol{\sigma}+\mathbf{A}_{12} p=\mathbf{b}_{1} \quad \text { continuum equilibrium } \\
& \mathbf{A}_{21} \boldsymbol{\sigma}+\mathbf{A}_{22} p=\mathbf{b}_{2} \quad \text { discontinuity equilibrium } \\
& \text { stress boundary conditions } \\
& \mathbf{A}_{31} \boldsymbol{\sigma}+\mathbf{A}_{32} p \leq \mathbf{b}_{3} \quad \text { yield conditions }
\end{aligned}
$$

where $\mathbf{A}_{11}$ to $\mathbf{A}_{32}$ are coefficient matrices and $\boldsymbol{\sigma}=\left\{\boldsymbol{\sigma}_{1}, \ldots, \boldsymbol{\sigma}_{e}, \ldots, \boldsymbol{\sigma}_{n}\right\}^{\mathrm{T}}$ is a vector that collects the 


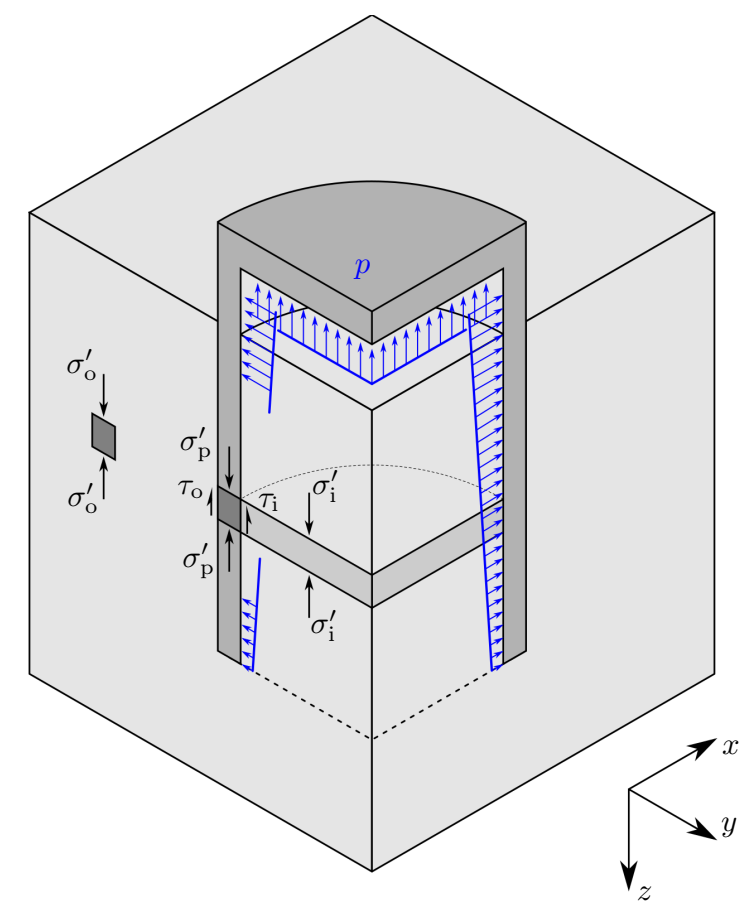

Figure 1: Model outline.

unknown stresses $\sigma_{e}$ for each of the $n$ elements:

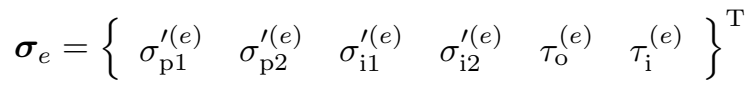

where $\sigma_{\mathrm{p} 1}^{\prime(e)}$ and $\sigma_{\mathrm{p} 2}^{\prime(e)}$ represent the stresses $\sigma_{\mathrm{p}}^{\prime}$ at the top and bottom of the pile element, for which a linear variation of stresses is assumed. Similarly, $\sigma_{\mathrm{i} 1}^{\prime(e)}$ and $\sigma_{\mathrm{i} 2}^{(e)}$ are the stresses $\sigma_{\mathrm{i}}^{\prime}$ at the top and bottom of the internal plug element. The shear stresses $\tau_{\mathrm{o}}^{(e)}$ and $\tau_{\mathrm{i}}^{(e)}$ are assumed constant over the element.

In the above equations, the hydraulic terms are separated to find an efficient calculation procedure to solve the optimisation problem. The set of equations corresponds to a linear objective function with linear equality and inequality constraints, for which many linear programming algorithms are readily available. The current implementation uses the optimize.linprog algorithm from the Python SciPy library.

The calculation procedure follows two steps: first, hydraulic equilibrium is calculated for the pile plug subject to a unit pressure using a finite element approach and secondly the finite element limit analysis model is used to calculate the break-out pressure. Both analysis steps use the same pile-soil discretisation. The following subsections describe first the hydraulic equilibrium equations followed by each of the components of the finite element limit analysis model. 


\subsection{Hydraulic finite element model}

A steady state pore-water pressure distribution is assumed inside the pile plug. Darcy's law for onedimensional seepage through an isotropic medium can be written as:

$$
k(z) \frac{\partial^{2} h}{\partial z^{2}}=0
$$

where $k$ is the soil permeability and $h$ is the hydraulic head. The water pressure distribution is calculated using a 1D finite element model corresponding to the plug elements in Figure 1. The discrete 1D finite element system is written in matrix notation as:

$$
\mathbf{q}=\mathbf{K h}
$$

where $\mathbf{q}$ is a vector that collects the nodal values of the flow at each node, $\mathbf{h}$ is a vector containing the nodal values of the hydraulic head and $\mathbf{K}$ is the hydraulic stiffness matrix. The hydraulic resistance at the base of the plug $K_{\text {base }}$ is used to capture the correct overpressure at the pile toe. This term is added to the stiffness matrix at the element corresponding to the base node. The formulation used for the base resistance is:

$$
K_{\text {base }}=5 \frac{k A_{\mathrm{i}}}{D}+\frac{k A_{\mathrm{i}}}{L}
$$

where $D$ is the pile diameter and $L$ is the embedded pile length. Equation (6) is calibrated to match with the pressure at the pile tip, following the simplified formulation of Houlsby and Byrne [11]. Their simplified formulation is an analytical approximation to the results from finite element calculations in soils with uniform permeability, for thin-walled caissons with $L / D$ ratios up to 0.8 . The corresponding ratio between the hydraulic head at the top of the plug and the bottom of the plug, denoted as $a$, is presented in Figure 2. At low $L / D$ ratios, our 1D FE formulation tends to $a=0.5$ instead of $a=0.46$. Houlsby and Byrne [11] commented that the factor should theoretically be 0.5 for $L / D=0$ and tend to zero for very large $L / D$ ratios, which is captured in the $1 \mathrm{D}$ model.

With the hydraulic finite element model, the water pressure distribution inside the pile is calculated for a unit pressure at the top of the soil plug. This normalised distribution is denoted $\overline{\boldsymbol{p}}$, and scales linearly with increased water flow.

\subsection{Equilibrium conditions}

The equilibrium conditions from equations (1a) and (1b) can be written in matrix notation for one element as:

$$
\left[\begin{array}{cccccc}
-\frac{1}{L_{\mathrm{e}}} & \frac{1}{L_{\mathrm{e}}} & 0 & 0 & -\frac{P_{\mathrm{o}}}{A_{\mathrm{p}}} & -\frac{P_{\mathrm{i}}}{A_{\mathrm{p}}} \\
0 & 0 & -\frac{1}{L_{\mathrm{e}}} & \frac{1}{L_{\mathrm{e}}} & 0 & \frac{P_{\mathrm{i}}}{A_{\mathrm{i}}}
\end{array}\right] \boldsymbol{\sigma}_{e}+\left[\begin{array}{c}
0 \\
-\frac{\bar{p}_{1}^{(e)}}{L_{\mathrm{e}}}+\frac{\bar{p}_{2}^{(e)}}{L_{\mathrm{e}}}
\end{array}\right] p=\left[\begin{array}{c}
\gamma_{\mathrm{p}}^{\prime} \\
\gamma_{\mathrm{s}}^{\prime}
\end{array}\right]
$$

where $L_{\mathrm{e}}$ is element length and $\bar{p}_{1}^{(e)}$ and $\bar{p}_{2}^{(e)}$ are the normalised overpressures at the top and bottom of the element. 

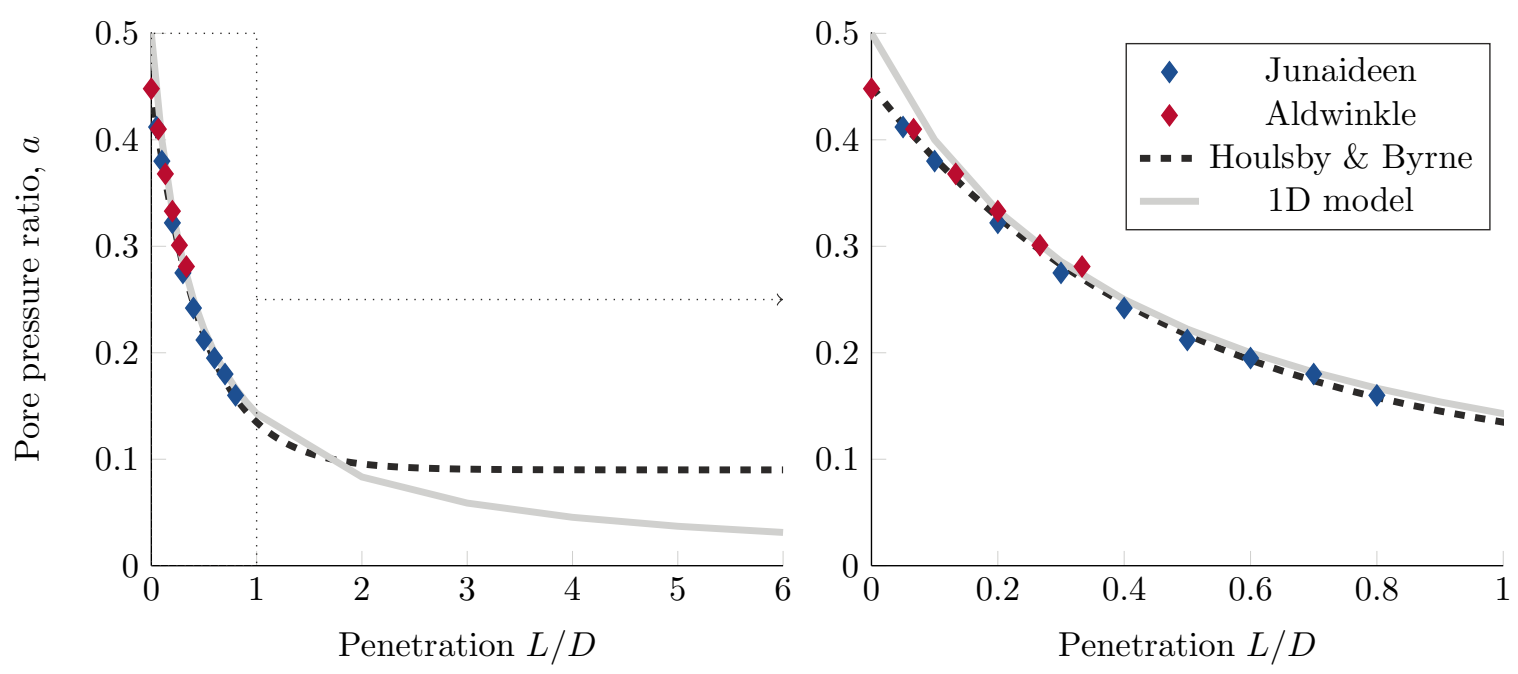

Figure 2: Comparison of the pile tip pressure using the 1D finite element hydraulic model with the formula of Houlsby and Byrne [11] and two separate studies presented in their paper.

\subsection{Discontinuity conditions}

In $2 \mathrm{D}$ and $3 \mathrm{D}$ finite element limit analysis, discontinuity conditions are used to specify that the normal and shear stresses at nodal pairs are the same. Although the normal and shear stresses are continuous along the element boundaries, the tangential normal stress may jump. In the $1 \mathrm{D}$ analysis, only the vertical stresses are considered in the equilibrium equations for the pile and soil plug:

$$
\left[\begin{array}{cccc}
1 & 0 & -1 & 0 \\
0 & 1 & 0 & -1
\end{array}\right]\left[\begin{array}{c}
\sigma_{\mathrm{p} 2}^{\prime(e)} \\
\sigma_{\mathrm{i} 2}^{\prime(e)} \\
\sigma_{\mathrm{p} 1}^{\prime(e+1)} \\
\sigma_{\mathrm{i} 1}^{\prime(e+1)}
\end{array}\right]=\left[\begin{array}{l}
0 \\
0
\end{array}\right]
$$

where $\sigma_{\mathrm{p} 2}^{\prime(e)}$ and $\sigma_{\mathrm{p} 1}^{\prime(e+1)}$ are the pile stresses at the bottom of element $e$ and the top of $e+1$ respectively, and similarly for the internal plug elements.

\subsection{Boundary conditions}

Two boundary conditions are defined: (1) zero vertical effective stress at the top of the soil plug and (2) a link between the applied pressure and the upwards force on the pile, also considering the weight of the structure applied at the top node $W_{\text {top }}$.

$$
\begin{array}{r}
\sigma_{\mathrm{i}}^{\prime}(z=0)=0 \\
\sigma_{\mathrm{p}}^{\prime}(z=0) A_{\mathrm{p}}+p A_{\mathrm{i}}=W_{\text {top }}
\end{array}
$$


The above equations are written in matrix notation as:

$$
\left[\begin{array}{cc}
1 & 0 \\
0 & A_{\mathrm{p}}
\end{array}\right]\left[\begin{array}{c}
\sigma_{\mathrm{i} 1}^{\prime(1)} \\
\sigma_{\mathrm{p} 1}^{\prime(1)}
\end{array}\right]+\left[\begin{array}{c}
0 \\
A_{\mathrm{i}}
\end{array}\right] p=\left[\begin{array}{c}
0 \\
W_{\mathrm{top}}
\end{array}\right]
$$

noting that the normalised overpressure at the top of the plug is set to unity, so that the resulting load multiplication factor obtained from the FELA can be directly interpreted as the required overpressure to reach the computed failure mechanism.

\subsection{Yield conditions}

The yield conditions are defined for the outside shaft resistance, the inside shaft resistance, and the plug base resistance. Following the API [5] pile capacity method, the yield conditions for the shaft resistance are:

$$
\begin{aligned}
\text { Sand } & \left|\tau_{\mathrm{i}}\right| \leq \beta_{0} \sigma_{\mathrm{v} 0}^{\prime}+\beta_{\mathrm{p}}\left(\sigma_{\mathrm{i}}^{\prime}-\sigma_{\mathrm{v} 0}^{\prime}\right) \\
\left|\tau_{\mathrm{o}}\right| & \leq \beta_{0} \sigma_{\mathrm{v} 0}^{\prime} \\
\text { Clay } & \left|\tau_{\mathrm{i}}\right| \leq \alpha s_{\mathrm{u}} \\
\left|\tau_{\mathrm{o}}\right| & \leq \alpha s_{\mathrm{u}}
\end{aligned}
$$

where $\beta_{0}=K_{0} \tan \delta$ and $\beta_{\mathrm{p}}=\nu /(1-\nu) \tan \delta$, with $K_{0}$ the initial lateral stress coefficient, $\delta$ the interface friction angle and $\nu$ the Poisson coefficient. For clay, $s_{\mathrm{u}}$ is the undrained shear strength and $\alpha$ is the interface shear coefficient. In the API design guidance for sand, the shaft friction contains a limiting value, however, the results from Balder et al. [4] indicate a strong decrease in the required overpressure during extraction in sand which would not be captured with a constant limiting shear stress. Therefore, the limits are not incorporated in the current analysis. The equations above are written in matrix form as:

$$
\text { Sand } \begin{array}{cccc}
{\left[\begin{array}{cccc}
-\beta_{\mathrm{p}} / 2 & -\beta_{\mathrm{p}} / 2 & 0 & 1 \\
-\beta_{\mathrm{p}} / 2 & -\beta_{\mathrm{p}} / 2 & 0 & -1 \\
0 & 0 & 1 & 0 \\
0 & 0 & -1 & 0
\end{array}\right]\left[\begin{array}{c}
\sigma_{\mathrm{i} 1}^{\prime(e)} \\
\sigma_{\mathrm{i} 2}^{\prime(e)} \\
\tau_{\mathrm{o}}^{(e)} \\
\tau_{\mathrm{i}}^{(e)}
\end{array}\right] \leq} & \leq\left[\begin{array}{c}
\left(\beta_{0}-\beta_{\mathrm{p}}\right) \sigma_{\mathrm{v} 0}^{\prime} \\
\left(\beta_{0}-\beta_{\mathrm{p}}\right) \sigma_{\mathrm{v} 0}^{\prime} \\
\beta_{0} \sigma_{\mathrm{v} 0}^{\prime} \\
\beta_{0} \sigma_{\mathrm{v} 0}^{\prime}
\end{array}\right] \\
\text { Clay } & {\left[\begin{array}{cc}
0 & 1 \\
0 & -1 \\
1 & 0 \\
-1 & 0
\end{array}\right]\left[\begin{array}{l}
\alpha s_{\mathrm{u}}^{(e)} \\
\tau_{\mathrm{i}}^{(e)}
\end{array}\right]}
\end{array}
$$

For the base resistance, the yield conditions according to the API design guidance are:

$$
\begin{array}{cccl} 
& 0 \leq & \sigma_{\mathrm{i}}^{\prime}(z=L) & \leq N_{\mathrm{q}} \sigma_{\mathrm{v} 0}^{\prime} \\
\text { Sand } & 0 \leq & \sigma_{\mathrm{p}}^{\prime}(z=L) & \leq N_{\mathrm{q}} \sigma_{\mathrm{v} 0}^{\prime} \\
& 0 \leq & \sigma_{\mathrm{i}}^{\prime}(z=L)+p_{\mathrm{i}}(z=L) & \leq 9 s_{\mathrm{u}} \\
\text { Clay } & 0 \leq 1 & & \leq 9 s_{\mathrm{u}}
\end{array}
$$


Table 1: Foundation pile geometry.

\begin{tabular}{lcc}
\hline Parameter & \multicolumn{2}{c}{ Value } \\
\hline Outer diameter & $D$ & $8 \mathrm{~m}$ \\
Embedded length & $L$ & $24 \mathrm{~m}$ \\
Wall thickness & $t$ & $100 \mathrm{~mm}$ \\
Submerged unit weight & $\gamma_{\mathrm{p}}^{\prime}$ & $67.2 \mathrm{kN} / \mathrm{m}^{3}$ \\
Submerged pile weight & $W_{\text {pile }}^{\prime}$ & $800 \mathrm{t}$ \\
\hline
\end{tabular}

where $N_{\mathrm{q}}$ is the bearing capacity factor in sand. The equations are written in matrix form for each element as:

$$
\begin{aligned}
& \text { Sand }\left[\begin{array}{cc}
0 & 1 \\
0 & -1 \\
1 & 0 \\
-1 & 0
\end{array}\right]\left[\begin{array}{c}
\sigma_{\mathrm{p} 2}^{\prime(n)} \\
{\sigma^{\prime} 2}^{(n)}
\end{array}\right] \quad \leq\left[\begin{array}{c}
N_{\mathrm{q}} \sigma_{\mathrm{v} 0}^{\prime} \\
0 \\
N_{\mathrm{q}} \sigma_{\mathrm{v} 0}^{\prime} \\
0
\end{array}\right] \\
& \text { Clay }\left[\begin{array}{cc}
0 & 1 \\
0 & -1 \\
1 & 0 \\
-1 & 0
\end{array}\right]\left[\begin{array}{c}
\sigma_{\mathrm{p} 2}^{\prime(n)} \\
{\sigma_{\mathrm{i} 2}^{\prime}}^{(n)}
\end{array}\right]+\left[\begin{array}{c}
\bar{p}_{2}^{(n)} \\
-\bar{p}_{2}^{(n)} \\
0 \\
0
\end{array}\right] p \leq\left[\begin{array}{c}
9 s_{\mathrm{u}} \\
0 \\
9 s_{\mathrm{u}} \\
0
\end{array}\right]
\end{aligned}
$$

\section{Results}

\subsection{Monopile and soil conditions}

The 1D FELA model is applied to a monopile foundation with dimensions as specified in Table 1. Four soil conditions are analysed: homogeneous sand, homogeneous clay, sand over clay and clay over sand. The interface for the two-layer soil conditions is taken at $12 \mathrm{~m}$ depth, which is half of the embedded pile length. The water unit weight $\gamma_{\mathrm{w}}$ is taken as $10 \mathrm{kN} / \mathrm{m}^{3}$. The soil parameters for the simulated results are given in Table 2. Each simulation uses 48 elements along the pile length. A sensitivity study on the number of elements is performed later in this section.

\subsection{Homogeneous sand}

In the homogeneous sand case, the pile is extracted at a hydraulic pressure of $2.91 \mathrm{MPa}(=29.1 \mathrm{bar})$. The first row in Figure 3 shows the vertical effective stresses, shaft friction and the hydraulic pressure along the pile length at the break-out pressure for this case. Due to the hydraulic gradient inside the plug, the inside vertical effective stresses and shaft friction are significantly higher compared to the corresponding stresses 
Table 2: Soil parameters.

\begin{tabular}{|c|c|c|c|}
\hline Soil type & & Sand & Clay \\
\hline Effective unit weight & $\gamma_{\mathrm{s}}^{\prime}$ & $10 \mathrm{kN} / \mathrm{m}^{3}$ & $10 \mathrm{kN} / \mathrm{m}^{3}$ \\
\hline Lateral earth pressure coefficient & $K_{0}$ & 0.5 & NA \\
\hline Bearing capacity factor & $N_{\mathrm{q}}$ & 40 & $\mathrm{NA}$ \\
\hline Interface friction angle & $\delta$ & $30^{\circ}$ & NA \\
\hline Poisson coefficient & $\nu$ & 0.4 & NA \\
\hline Undrained shear strength & $s_{\mathrm{u}}$ & NA & $100 \mathrm{kPa}$ \\
\hline Interface shear factor & $\alpha$ & NA & 0.5 \\
\hline Permeability & $k$ & $1 \mathrm{e}-4 \mathrm{~m} / \mathrm{s}$ & $1 \mathrm{e}-9 \mathrm{~m} / \mathrm{s}$ \\
\hline
\end{tabular}

at the outside. This increase of vertical soil stresses reduces further down the pile due to the development of the inner shaft friction.

\subsection{Homogeneous clay}

The second row in Figure 3 presents the results from the homogeneous clay case at a hydraulic pressure of $1.28 \mathrm{MPa}$ (=12.8 bar). At this pressure, plug failure occurs since the base resistance $\left(9 s_{\mathrm{u}}=900 \mathrm{kPa}\right)$ and the inside shaft resistance are fully mobilised, but the outside shaft resistance is not. This analysis shows the risk of other failure mechanisms during hydraulic pile extraction. The onset of plug failure is analysed in more detail later in this section. The outside shaft resistance is seemingly randomly distributed between the limits set out in the yield conditions. This is a consequence of the fact that the stress distribution is not unique. However, the average of the outside shaft friction does correspond to the equilibrium conditions of the system.

\subsection{Sand over clay}

The third row in Figure 3 shows the results of sand over clay. Pile extraction occurs at a hydraulic pressure of $0.95 \mathrm{MPa}(=9.5 \mathrm{bar})$, which is significantly lower than the sand case and also lower than the onset of failure in the homogeneous clay case. The base resistance is mobilised for $92 \%$ in the analysis. This mobilisation factor can be used in pile extraction assessments to identify potential risks during extraction. The vertical effective stresses in the sand layer of the plug are reduced compared to the outside shaft resistance. Due to the underlying clay layer, there is virtually no hydraulic gradient in the sand layer, and the inside shaft friction results in a decrease of the vertical effective stresses. A clay layer at the bottom of the pile plug can therefore have a significant beneficial effect on the required extraction pressure. 


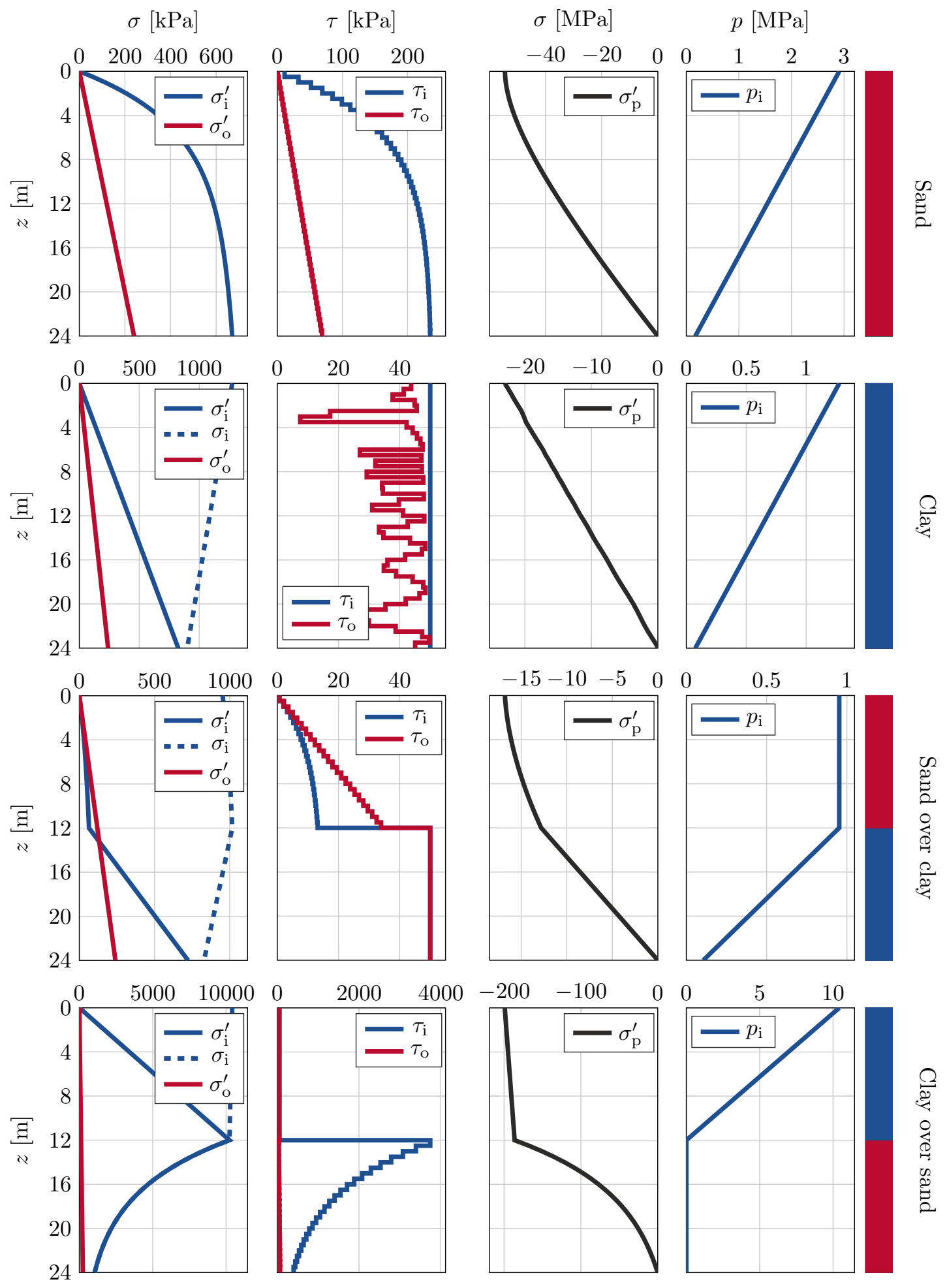

Figure 3: Results for the sand, clay, sand over clay and clay over sand cases. 


\subsection{Clay over sand}

The fourth row in Figure 3 shows the results of the clay over sand case. Pile extraction occurs at a hydraulic pressure of $10.42 \mathrm{MPa}$ (=104.2 bar), which is significantly higher than the sand case. There is virtually no gradient in the hydraulic pressure in the clay layer, but the applied overpressure is transferred directly to the top of the sand layer as a vertical effective stress. This significantly increases the shaft resistance in the sand layer, resulting in a very high required pressure.

Failure of the pile is assessed using Barlow's equation:

$$
p=2 \sigma_{\mathrm{h}} t / D
$$

where $\sigma_{\mathrm{h}}$ is the hoop stress in the pile. The extraction overpressure of 104.2 bar results in hoop stresses of $417 \mathrm{MPa}$. This value is beyond the $355 \mathrm{MPa}$ yield strength of S355 steel which is commonly used for offshore structures. Safety factors on the yield strength, and reduction factors due to corrosion of foundation piles which have been offshore for 20 to 25 years need to be considered when assessing the maximum allowed operating pressure. Safety considerations must also be met when applying high pressures.

The above analyses illustrate the main mechanisms during hydraulic pile extraction in uniform and layered soil conditions.

\subsection{Sensitivity analysis number of elements}

Figure 4 illustrates the calculation error with number of elements in the simulation. An exact solution was found in all clay simulations since the ultimate shaft resistance is constant for this case. The calculation error is assessed by comparing the results with a simulation of 196 elements. The figure shows that the error decreases rapidly with number of elements. For the sand and sand over clay cases, a limited error $(<1 \mathrm{e}-3)$ was found using less than 10 elements. For these cases, the simulations provided a lower bound for the exact solution. In the clay over sand case, a larger error was found and a larger number of elements is required to achieve a limited error of $0.1 \%$. In this case, an upper bound value was calculated for the exact solution. By substituting equation (12) in equation (1a) for sand layers, one can derive analytically that the stresses inside the pile plug are convex when:

$$
\sigma_{\mathrm{i}}^{\prime}>\frac{A_{\mathrm{i}}}{\beta_{\mathrm{p}} P_{\mathrm{i}}}\left(\frac{\beta_{0}}{\beta_{\mathrm{p}}} \gamma_{\mathrm{s}}^{\prime}-\frac{\partial p_{\mathrm{i}}}{\partial z}\right)-\frac{\beta_{0}-\beta_{\mathrm{p}}}{\beta_{\mathrm{p}}} \sigma_{\mathrm{v} 0}^{\prime}
$$

In cases where the shape of the soil stresses in the plug is convex, linear elements overestimate the soil stresses within the element. This causes higher shaft resistance on the inner pile area, and in the clay over sand case, this results in an upper bound to the exact solution. The derivation shows that for specific cases in hydro-mechanical simulations, the lower-bound FELA approach from Sloan [9] may not necessarily result in a strict lower bound solution. Generally, it can be concluded that the model produces accurate results with limited $(<100)$ number of elements in all of the analyses presented here. 


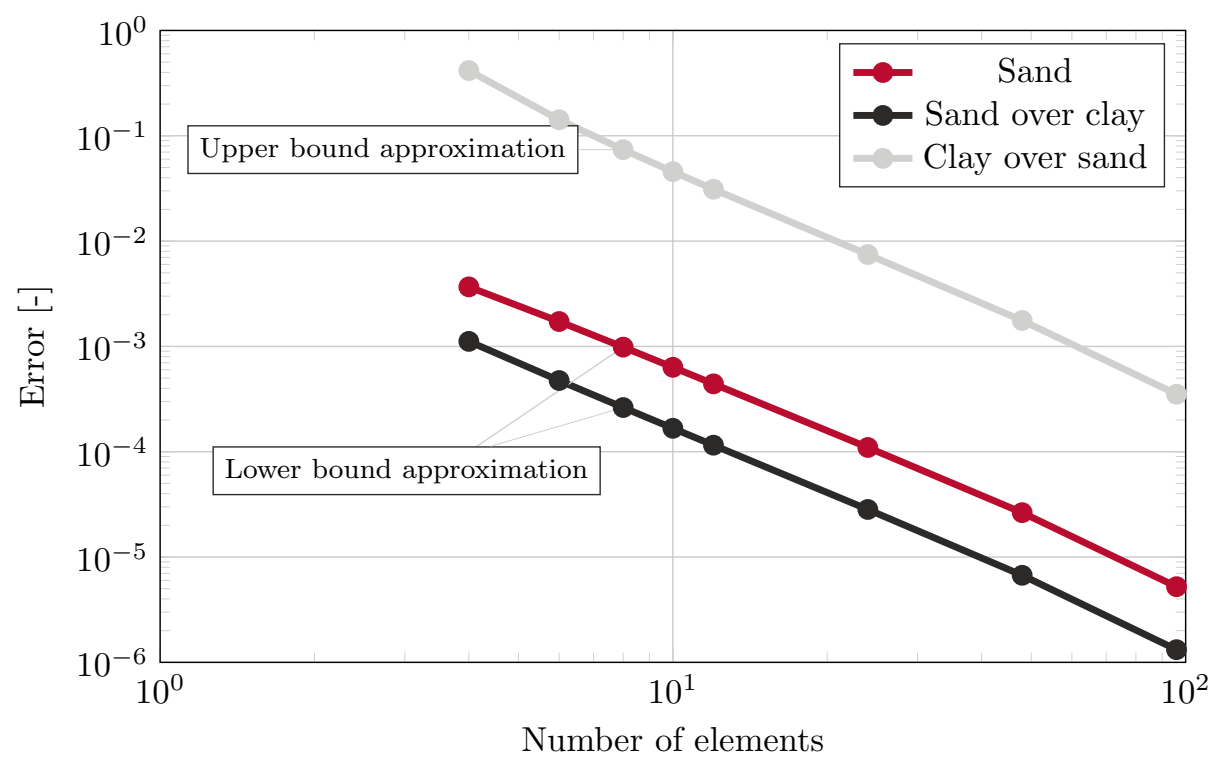

Figure 4: Sensitivity study on the calculation error based on the number of elements.

\subsection{Effect of pile length}

The effect of the pile length on the break-out pressure is assessed for the four cases discussed before (in case of layered soils, the interface is always at $12 \mathrm{~m}$ ). The results are shown in Figure 5. For the sand case, the required pressure increases super-linearly, which is caused by the interaction of the hydraulic pressure gradient and the shaft resistance. In the clay case, the required pressure increases linearly up to $20 \mathrm{~m}$. Beyond this depth, failure of the plug occurs as indicated in the previous analysis for an embedment depth of $24 \mathrm{~m}$.

In the top $12 \mathrm{~m}$, the sand and sand over clay case give the same results, and similarly for the clay and clay over sand case since the layer boundary is defined at $12 \mathrm{~m}$ depth. In the sand over clay case, the break-out pressure decreases at $12 \mathrm{~m}$ depth due to the beneficial effect of the clay layer. The required overpressure then increases linearly until failure of the plug occurs at $26 \mathrm{~m}$ embedment length. In the clay over sand case, the required overpressure increases even more significantly than the sand case beyond $12 \mathrm{~m}$ depth. This is caused by the direct transfer of the pressure as a vertical effective stress at the top of the sand layer due to the presence of the clay layer.

The complete analysis of the effect of the pile length on the extraction pressure (48 cases) was calculated in $13 \mathrm{~s}$ on a laptop with an Intel ${ }^{\circledR} \mathrm{Core}^{\mathrm{TM}} \mathrm{i} 5-6200 \mathrm{u}$ CPU processor. The calculation time includes assembly of the matrices for each case and the calculation of the solution using the linear programming optimisation method. This is much faster compared to 2D axisymmetric finite element analyses, which may be considered as an alternative to simulate this problem. The limited computational time makes the 1D FELA method suitable for preliminary analyses to assess ranges in pile geometry and soil conditions as well as detailed 


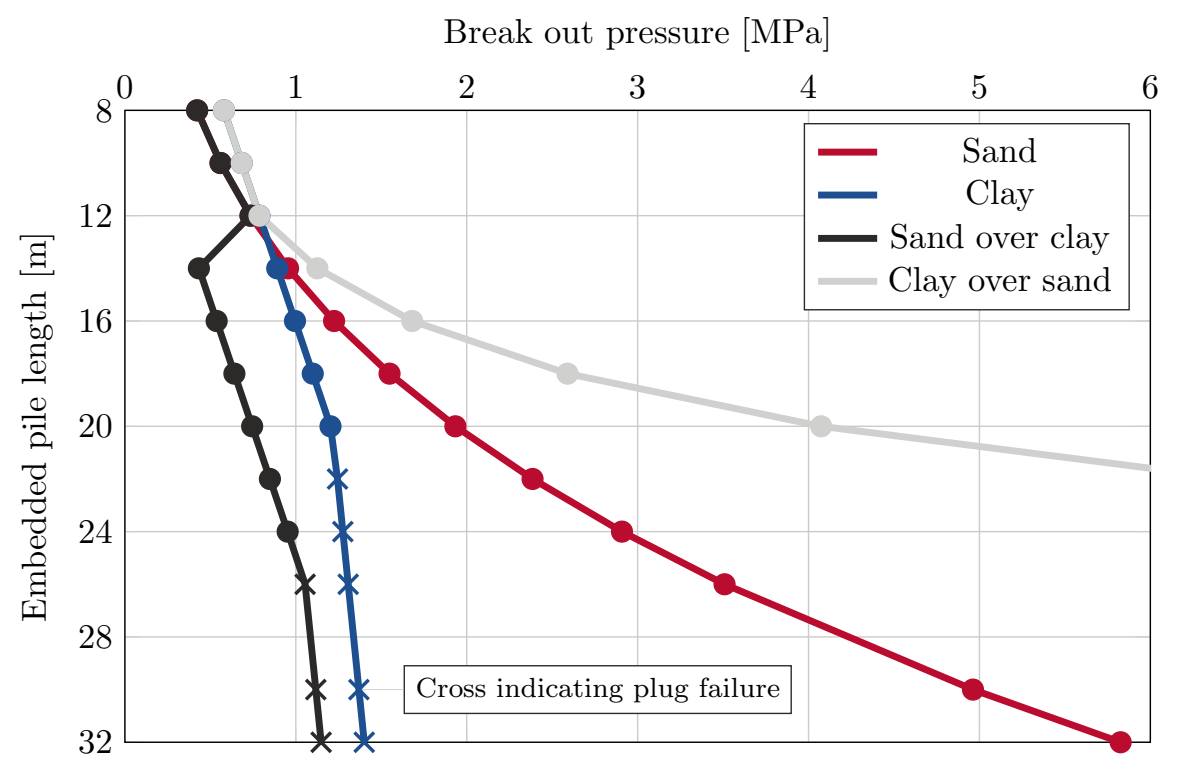

Figure 5: Break-out pressure vs. embedded pile length.

calculations for extraction of many foundation piles in an offshore wind farm.

\section{Conclusion}

This paper presents a calculation method for hydraulic pressure extraction of pile foundations. The method is based on a 1D finite element limit analysis model, suitable to incorporate existing axial pile capacity models such as the API, UWA and ICP methods. The 1D model approximates the 3D stress distribution inside and outside of the pile based on analytical expressions. Hydraulic pressure extraction is analysed for four different soil conditions: homogeneous sand, clay, layered sand over clay and clay over sand. The analyses in sand show a significant increase in the plug shaft resistance due to the hydraulic gradient, resulting in a super-linear increase of break-out pressure with embedment depth. In clay soils, the break-out pressure increases linearly, but plug failure may occur at large embedment depths. Soil layering can have a significant effect on the break-out pressure: in the sand over clay case, the break-out pressure is reduced and in the clay over sand case, the break-out pressure is increased significantly. Due to the limited computational cost, the presented method provides a fast assessment tool, which can be used as a scoping tool in a preliminary design or in a detailed assessment for an entire wind farm, where a large number of locations need to be analysed.

\section{References}

[1] P. Zhang, H. Ding, C. Le, Installation and removal records of field trials for two mooring dolphin platforms with three suction caissons, Journal of waterway, port, coastal, and ocean engineering 139 (6) (2013) 502-517. doi:10.1061/(ASCE) 
WW. 1943-5460.0000206.

[2] L. S. D. Lorenti, D. Y. N. Shum, B. M. Lehane, Field trial and numerical back-analysis of suction caisson extraction in Hong Kong, in: International Conference on Offshore Mechanics and Arctic Engineering, Vol. 43475, 2009 , pp. $239-244$.

[3] B. M. Lehane, S. Elkhatib, S. Terzaghi, Extraction of suction caissons in sand, Géotechnique 64 (9) (2014) $735-739$.

[4] T. Balder, D. A. de Lange, A. S. K. Elkadi, P. J. P. Egberts, W. J. A. P. Beuckelaers, M. Coronel, J. van Dijk, R. Atkinson, H. J. Luger, Hydraulic pile extraction scale tests (HyPE-ST): experimental design \& preliminary results, in: International Symposium on Frontiers in Offshore Geotechnics, Austin, Texas, 2020.

[5] API, Recommended Practice for Planning, Designing and Constructing Fixed Offshore Platform - Working Stress Design RP 2A-WSD, American Petroleum Institute, Washington, D.C., 2002.

[6] R. Jardine, F. Chow, R. Overy, J. Standing, ICP design methods for driven piles in sands and clays, Vol. 112, Thomas Telford London, 2005.

[7] B. M. Lehane, J. A. Schneider, X. Xu, The UWA-05 method for prediction of axial capacity of driven piles in sand, in: International Symposium on Frontiers in Offshore Geomechanics, Perth, Western Australia, 2005, pp. 683-690.

[8] S. W. Sloan, Lower bound limit analysis using finite elements and linear programming, International Journal for Numerical and Analytical Methods in Geomechanics 12 (1) (1988) 61-77. doi:10.1002/nag.1610120105.

[9] S. W. Sloan, Geotechnical stability analysis, Géotechnique 63 (7) (2013) 531-572.

[10] K. Krabbenhoft, L. Damkilde, A general non-linear optimization algorithm for lower bound limit analysis, International Journal for Numerical Methods in Engineering 56 (2) (2003) 165-184.

[11] G. T. Houlsby, B. W. Byrne, Design procedures for installation of suction caissons in sand, Proceedings of the Institution of Civil Engineers - Geotechnical Engineering 158 (3) (2005) 135-144. doi:10.1680/geng.2005.158.3.135. 